\title{
Effect of Dietary Conjugated Linoleic Acid Supplementation on Early Inflammatory Responses during Cutaneous Wound Healing
}

\author{
Na-Young Park, Giuseppe Valacchi, and Yunsook Lim \\ Department of Food and Nutrition, Research Institute of Science for Human Life, Kyung Hee University, 1 Hoegi-dong, \\ Dongdaemun-gu, Seoul 130-761, Republic of Korea \\ Correspondence should be addressed to Yunsook Lim, ylim@khu.ac.kr
}

Received 22 January 2010; Accepted 6 July 2010

Academic Editor: Chiara De Luca

Copyright ( $) 2010$ Na-Young Park et al. This is an open access article distributed under the Creative Commons Attribution License, which permits unrestricted use, distribution, and reproduction in any medium, provided the original work is properly cited.

Inflammatory response is considered the most important period that regulates the entire healing process. Conjugated linoleic acid (CLA), a class of linoleic acid positional and geometric isomers, is well known for its antioxidant and anti-inflammatory properties. We hypothesized that dietary CLA supplementation accelerates cutaneous wound healing by regulating antioxidant and anti-inflammatory functions. To investigate wound closure rates and inflammatory responses, we used a full-thickness excisional wound model after 2-week treatments with control, $0.5 \%$, or $1 \%$ CLA-supplemented diet. Mice fed dietary CLA supplementation had reduced levels of oxidative stress and inflammatory markers. Moreover, the wound closure rate was improved significantly in mice fed a 1\% CLA-supplemented diet during early stage of wound healing (inflammatory stage). We conclude that dietary CLA supplementation enhances the early stage of cutaneous wound healing as a result of modulating oxidative stress and inflammatory responses.

\section{Introduction}

Wound healing is an essential procedure that helps maintain homeostasis and integrate tissue injured by physical, chemical, bacterial, or viral insults [1-3]. Generally, there are three major stages of wound healing that overlap in time and space: inflammation, proliferation, and remodeling [4]. Because it is involved in producing growth factors and cytokines that coordinate the cell and tissue movements necessary for repair, the inflammatory response is considered the most important period that regulates the entire healing process [57]. The initial event of the inflammatory stage during wound healing is the infiltration of neutrophils and macrophages into the wound site to attack contaminating bacteria and to phagocytose cellular debris resulting in the production of reactive oxygen species (ROS). Furthermore, neutrophils and macrophages are both major sources and targets of proinflammatory cytokines such as IL- $1 \alpha$, IL- $1 \beta$, IL- 6 , and TNF- $\alpha$ that have been shown to be crucial mediators during cutaneous inflammatory processes $[4,5]$. For example, IL- $1 \beta$ and TNF- $\alpha$, primary proinflammatory cytokines, promote nuclear factor $\kappa \mathrm{B}(\mathrm{NF} \kappa \mathrm{B})$ activation and ROS production in inflammatory cells $[8-10] . \mathrm{NF} \kappa \mathrm{B}$ is a redox-sensitive transcription factor that acts as a central protein regulating the transcription of many inflammatory mediators including cyclooxygenase (COX)-2, a rate-limiting enzyme in the biosynthesis of prostaglandins during inflammation and immune response. Because of its essential role in controlling inflammatory responses, regulation of $\mathrm{NF} \kappa \mathrm{B}$ activation by the oxidative stress present during the early inflammatory cascade may be advantageous in the treatment of wounds.

Cells in injured and inflamed tissues are able to protect themselves with a well-equipped array of antioxidant enzymes, such as glutathione peroxidase (GPX), catalase, superoxide dismutases (SODs), and heme oxygenases (HO). SODs dismutate superoxide radical anions to $\mathrm{H}_{2} \mathrm{O}_{2}$ and water. A previous study has shown that mRNA levels of CuZnSOD and MnSOD were upregulated in the early inflammatory stage of cutaneous wound healing [11]. HO1 , the inducible isoform of $\mathrm{HO}$, shows protection against ROS as well. In mouse full-thickness excisional wounds, the mRNA and protein levels of HO-1 increased after wounding and subsequently declined until the wound was healed [11], which proposes a role of $\mathrm{HO}-1$ in a protective function through reduction of inflammation [12]. 
Despite the remarkable significance of inflammation, most studies have focused on the later stage of wound healing, the remodeling stage, especially in collagen formation and maturation [13]. Our group previously demonstrated that $\mathrm{N}$-acetylcysteine and zinc known as antioxidant nutrients played important role in regulation of wound healing rate and inflammatory response during wound healing procedure $[1,14]$. However, except these two antioxidant nutrients, little is known on the molecular mechanism that controls the wound healing rate.

Conjugated linoleic acid (CLA) refers to a class of the essential fatty acid linoleic acid positional and geometric isomers, marked by conjugated double bond [15]. CLA was found naturally in meat and dairy products from cows and sheep due to the process of bacterial biohydrogenation of linoleic acid (LA) in the rumen [16]. Interest in CLA came first from its anticarcinogenic action [17] and now there is a growing literature showing the beneficial effects of CLA, such as antiadipogenic $[15,18]$, antiatherogenic $[19,20]$, antidiabetogenic $[21,22]$, anti-inflammatory [2326], and antioxidant properties [27-29]. It was suggested that CLA is effective in improving skin disorders in animals [30]. In addition, Hwang et al. have reported that CLA inhibited $\mathrm{NF} \kappa \mathrm{B}$-driven $\mathrm{COX}-2$ protein expression in mouse skin carcinogenesis [31]. However, the effect of CLA on cutaneous wound healing is poorly documented.

We hypothesized that dietary CLA supplementation promotes cutaneous wound healing through modulation of inflammatory responses including $\mathrm{NF} \kappa \mathrm{B}$ activation. In particular, we used a cutaneous full-thickness excisional wound model to examine the effects of dietary CLA supplementation on the rate of wound closure, and the temporal expression levels of $\mathrm{pI} \kappa \mathrm{B} \alpha, \mathrm{COX}-2, \mathrm{CuZnSOD}, \mathrm{MnSOD}$, and $\mathrm{HO}-1$ protein levels during the early inflammatory stage of cutaneous wound healing.

\section{Materials and Methods}

2.1. Animals and Diets. Female CrljBgi:CD-1 (ICR) mice (4 wks old) were purchased from Orient Bio Inc. (Gyeonggido, South Korea) and lodged in individual plastic cages at temperature- and humidity-controlled room (12-hr light:dark cycle) with allowed access to distilled water and food. Body weights and food intake were measured every three days and every day, respectively. Mice were acclimated for 7 days (d) before starting dietary treatments. They were fed a modified AIN-93G rodent diet supplemented with 0 (control), $0.5 \%$, or $1 \%$ CLA for 2 wks (Han Live R\&D, Gyeonggi-do, South Korea) (Tables 1 and 2). All mice were used in accordance with animal protocols approved by the Kyung Hee University Institutional Animal Care and Use Committee.

2.2. Wound Biopsy. Mice were anesthetized with isoflurane and the back of the mouse was shaved using an electronic clipper and sterilized using an alcohol swab. The wound biopsy model used in this experiment has been previously described [32]. The skin was then nipped and bent, and the
TABLE 1: Diet composition of experimental group.

\begin{tabular}{lccc}
\hline & \multicolumn{3}{c}{ Experimental diets* } \\
& Control & $0.5 \%$ CLA & $1 \%$ CLA \\
\hline & 20 & $g / 100 g$ \\
Casein & 39.7486 & 39.7486 & 39.7486 \\
Cornstarch & 13.2 & 13.2 & 13.2 \\
Dyetrose & 10 & 10 & 10 \\
Sucrose & 5 & 5 & 5 \\
Cellulose & 7 & 6.388 & 5.776 \\
Corn Oil & - & 0.612 & 1.224 \\
CLA & 0.0014 & 0.0014 & 0.0014 \\
$t$-Butylhydroquinone & 3.5 & 3.5 & 3.5 \\
Salt Mix \#210025 & 1.0 & 1.0 & 1.0 \\
Vitamin Mix \#310025 & 0.3 & 0.3 & 0.3 \\
L-Cystine & 0.25 & 0.25 & 0.25 \\
Choline Bitartarate & 100 & 100 & 100 \\
\hline Total & & &
\end{tabular}

TABLE 2: Major fatty acid composition in diets.

\begin{tabular}{lc}
\hline Fatty acids & Composition \% \\
\hline cis-9, trans-11 CLA & 37.99 \\
trans-10, cis-12 CLA & 39.09 \\
cis-9, cis-11 CLA & 3.36 \\
trans-9, trans-11 CLA & 1.22 \\
\hline Total CLA & 81.67 \\
\hline
\end{tabular}

full-thickness excisional wounds were made on the bent skin using a sterile biopsy punch $(4 \mathrm{~mm}$ diameter, Kai medical, Gifu City, Japan). Two round shape wounds on the dorsum, below the shoulder blades of each mouse were made to avoid self-licking.

2.3. Harvesting. Mice were sacrificed with an overdose of ethyl ether to gather tissue samples at the wound site. Each wound site at $0,24,48$, and 72 hours (hr) after wounding and at end point was harvested by a cutting area that covered the entire wound site.

2.4. Malondialdehyde Measurement. Levels of malondialdehyde (MDA) were measured as a marker of lipid peroxidation [33, 34]. Ten percent (weight/volume) liver tissues were homogenized with $0.15 \mathrm{M} \mathrm{KCl}$ buffer. $0.2 \mathrm{ml}$ of tissue homogenate, $0.2 \mathrm{ml}$ sodium dodecyl sulphate, $8.1 \%$ (weight/volume), and $3 \mathrm{ml} \mathrm{20 \%} \mathrm{acetic} \mathrm{acid-0.8 \%} \mathrm{TBA}$ mixture $(1: 1$, by volume) were added, to reach the volume of $4 \mathrm{ml}$. Samples were then blended, warmed for 60 minutes (min), maintained at $95^{\circ} \mathrm{C}$, and then cooled under tap water immediately. To each tube, $1 \mathrm{ml}$ distilled water and $5 \mathrm{ml}$ mixture of n-butanol and pyridine (15:1, by volume) were supplemented and shaken vigorously and centrifuged at $4,000 \mathrm{rpm}$ for $10 \mathrm{~min}$. The upper layer was aspirated 
out and absorbancy was measured at $532 \mathrm{~nm}$ using 1,1,3,3tetramethoxypropane as an external criterion.

2.5. Measurement of Wound Closure. Wounds from each mouse were photographed digitally every day, beginning on the day of wounding ( $\mathrm{d} 0$ ) with a criterion spot equal to the initial wound part placed beside the wound. The quantification of wound closure used in this experiment was previously described [35]. The rate of wound closure was demonstrated as the ratio of the wound size (each day after wounding) compared with the initial wound size. A smaller wound ratio indicates faster wound closure.

2.6. Preparation of Homogenized Skin Tissue Proteins and Western Blot. Skin tissues from the wound sites were homogenized in lysis buffer $(20 \mathrm{mM}$ Tris-HCl (Sigma, St. Louis, MO, USA), $150 \mathrm{mM} \mathrm{NaCl}_{2}$ (Duksan, Gyeonggi-do, South Korea), pH7.5, 1\% NP40 (Sigma), 0.5\% Na-deoxycholate stock (Sigma), 1mM EDTA (Duksan), and $0.1 \%$ sodium dodecyl sulfate (Sigma)) as previously described by our group [36]. The homogenates were incubated on ice for $20 \mathrm{~min}$ and centrifuged at $14,000 \mathrm{rpm}$ for $30 \mathrm{mins}$. The supernatants were stored at $-80^{\circ} \mathrm{C}$ until additional processing.

For Western blot analysis, samples $(60 \mu \mathrm{g}$ protein, determined using BioRad protein assay; BioRad, Hercules, CA, USA) were separated on 10\% SDS-PAGE gels and electrotransferred onto PVDF (polyvinylidene fluoride) membranes. After blocking in 5\% nonfat milk in PBSTween 20, the membranes were incubated with specific monoclonal and polyclonal antibodies against phosphorylated $\mathrm{I} \kappa \mathrm{B} \alpha(\mathrm{pI} \kappa \mathrm{B} \alpha)$ (Santa Cruz Biotechnology, Santa Cruz CA, USA, $1: 200$ ), COX-2 (Transduction Laboratories, Lexington KY, USA, $1: 250$ ), HO-1 (Stressgen, Victoria BC, Canada, 1:2000), CuZnSOD (Santa Cruz Biotechnology, $1: 500$ ), MnSOD (Stressgen, 1:5000), and $\beta$-actin (Santa Cruz Biotechnology, 1:200). Horseradish peroxidase conjugated antibody (Santa Cruz Biotechnology) was used as secondary antibody and bound antibodies were visualized by enhanced chemiluminescence (ECL Western Blotting Substrate, Pierce), captured on X-ray film (Agfa-Gevaert N.V.), and band densities were quantified using NIH image software.

2.7. Statistical Analysis. All values are expressed as means \pm SEM. Data were analyzed by 1-way ANOVA, and then differences among means were analyzed using Duncan's test. The relationships between body weight gain and wound size were evaluated by Pearson's correlation coefficients. For all tests, differences were considered significant at $P<.05$.

\section{Results}

3.1. Effect of Dietary CLA Supplementation on Body Weight and Food Intake. Dietary CLA supplementation significantly reduced the body weights gain in mice throughout the experimental periods compared to a control diet (Figure 1).

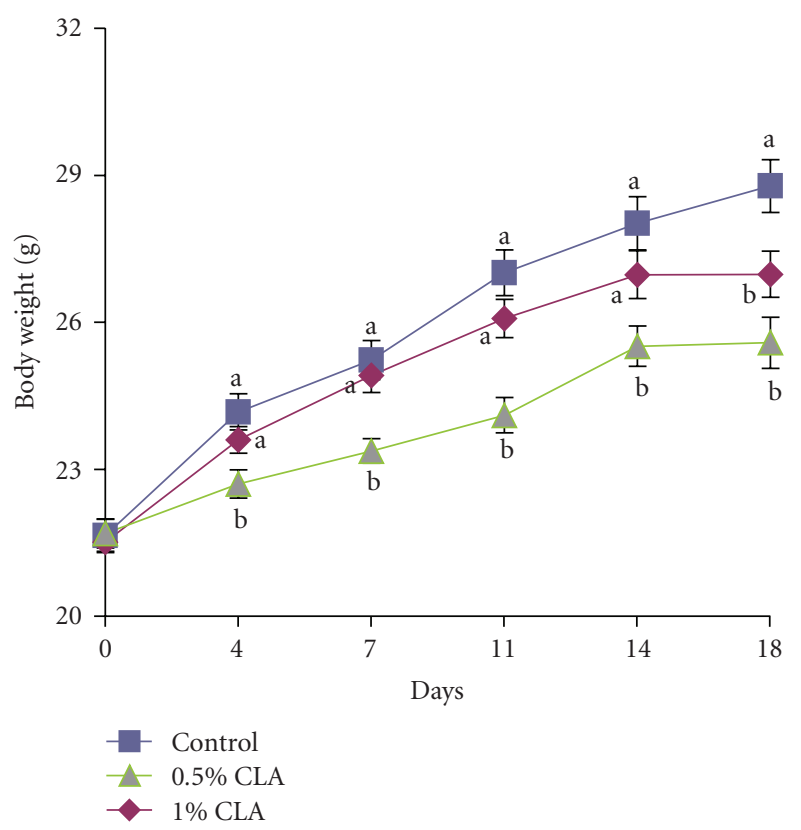

FIGURE 1: Changes in body weight in mice fed diets containing 0 (control), $0.5 \%$, or $1 \%$ CLA for 2 weeks. Values are means \pm SEM; $N=4$ to 6 in each group. Means at a time with a different letter are significantly different, $P<.05$.

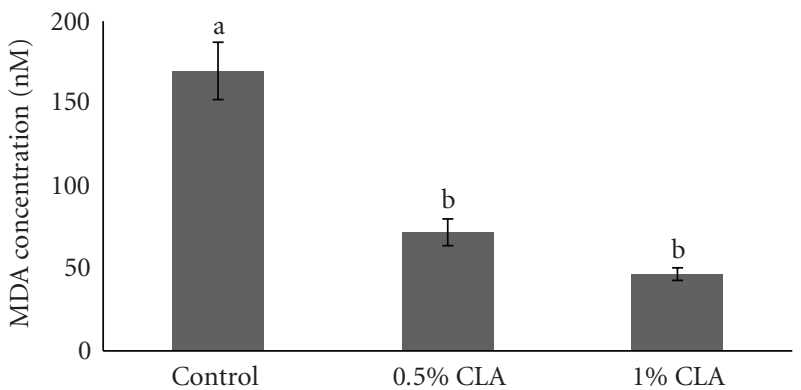

FIgure 2: Liver MDA levels in mice fed diets containing 0 (control), $0.5 \%$, or $1 \%$ CLA for 2 weeks. Values are means \pm SEM; $N=4$ to 6 in each group. Means with a different letter are significantly different, $P<.05$.

Particularly, body weight gain was lower in the 1\% CLAsupplemented group than the control and 0.5\% CLAsupplemented groups $(P<.05)$. The food intakes during the experiments were not significantly different among the groups (data not shown).

3.2. Effect of Dietary CLA Supplementation on MDA Levels of Mouse Liver. Dietary CLA supplementation resulted in a decrease of liver lipid peroxidation measured as MDA levels (Figure 2). Liver MDA levels were significantly lower in CLAsupplemented groups as compared to the controls (about 2.4- to 3.7-times, resp.). No differences between the $0.5 \%$ and the $1 \%$ CLA-supplemented groups were noted. 


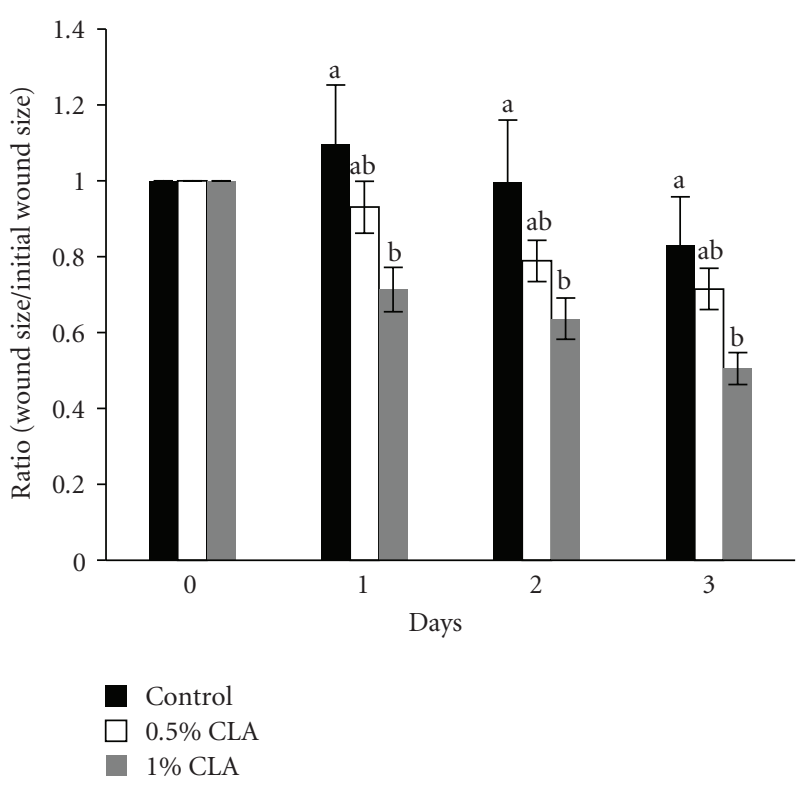

Figure 3: The rate of wound closure in mice fed diets containing 0 (control), $0.5 \%$, or $1 \%$ CLA for 2 weeks. The area of the wound of each time point was relative to the area of the wound on $\mathrm{d} 0$ (set at 1.0 ). Values are means $\pm \mathrm{SEM} ; N=4$ to 6 in each group. Means at a time with a different letter are significantly different, $P<.05$.

TABLE 3: Relationships (Pearson's correlation coefficients) between body weight gain and wound size.

\begin{tabular}{lccc}
\hline & \multicolumn{3}{c}{ Wound size } \\
& $\mathrm{d} 1(24 \mathrm{hr})$ & $\mathrm{d} 2(48 \mathrm{hr})$ & $\mathrm{d} \mathrm{3}(72 \mathrm{hr})$ \\
\hline Body weight gain & $.580^{*}$ & $.548^{*}$ & $.552^{*}$ \\
\hline${ }^{*} P<.05$. & &
\end{tabular}

\subsection{Effect of Dietary CLA Supplementation on Wound Clo-} sure Rate. The rate of wound closure in the 1\% CLAsupplemented group was significantly faster than those of the control and the $0.5 \%$ CLA-supplemented groups during the early stage of wound healing (Figure 3 ). Although not significant, the $0.5 \%$ CLA-supplemented groups showed a faster wound closure rate than the control, suggesting a dosedependent effect of CLA.

\subsection{Effect of Dietary CLA Supplementation on Relationships} between Body Weight Gain and Early Wound Size. We performed statistical analysis to identify correlations between body weight gain and early wound size as shown in Table 3 . Body weight was positively correlated to early wound size $(P<.05)$.

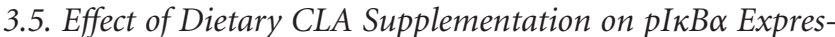
sion Levels. During wound healing, $\mathrm{pI} \kappa \mathrm{B} \alpha$ protein level increased in all groups. The expression levels of $\mathrm{pI} \kappa \mathrm{B} \alpha$ in the $1 \%$ dietary CLA supplemented group were significantly reduced starting at $48 \mathrm{hr}$ after wounding compared to the other groups (Figure 4).

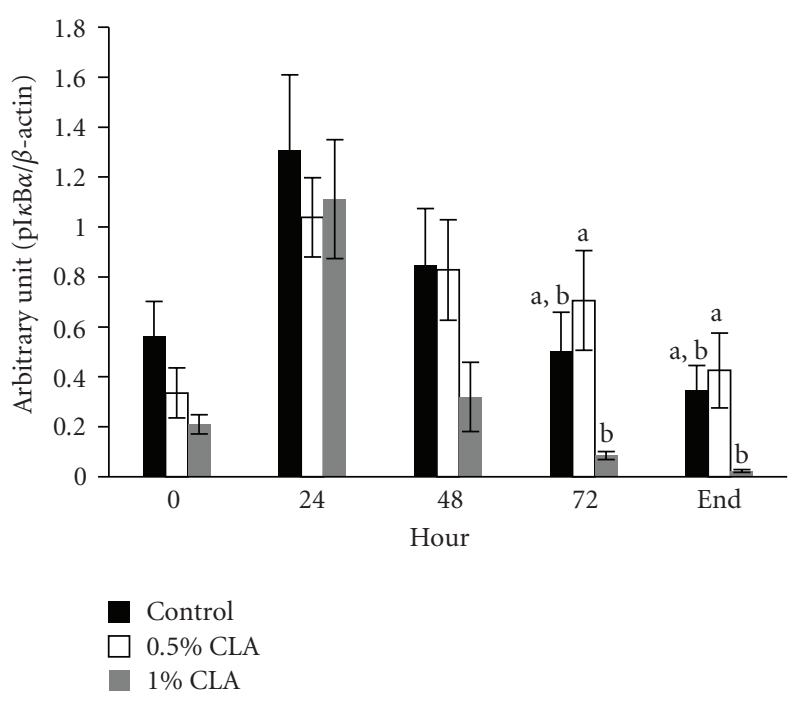

(a)

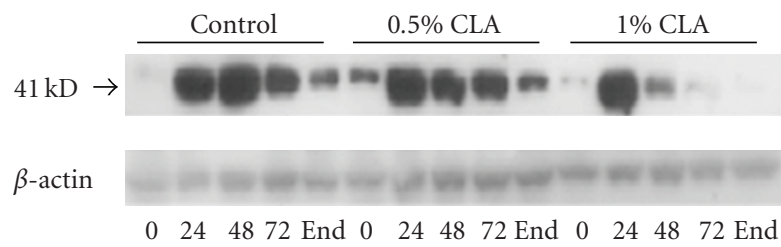

(b)

FIgURE 4: $\mathrm{pI} \kappa \mathrm{B} \alpha$ protein expression in cutaneous wounds of mice fed diets containing 0 (control), $0.5 \%$, or $1 \%$ CLA for 2 weeks. (a) Quantified $\mathrm{pI} \kappa \mathrm{B} \alpha$ protein expression levels determined by densitometry. Values are mean \pm SEM; $N=4$ to 6 in each group. Means at a time with a different letter are significantly different, $P<.05$. (b) $0 ; 0 \mathrm{hr}, 24 ; 24 \mathrm{hr}, 48 ; 48 \mathrm{hr}, 72 ; 72 \mathrm{hr}$ after wounding, end (wound is completely closed).

3.6. Effect of Dietary CLA Supplementation on COX-2 Expression in Mouse Skin. As shown in Figure 5, the expression of COX-2 protein was barely detectable at baseline $(0 \mathrm{hr})$, and it was induced in all groups after wounding. The expression levels of COX-2 at $24 \mathrm{hr}$ after wounding were remarkably reduced in the dietary CLA-supplemented mice $(P<.05)$ and returned to the steady levels in all groups at the end point.

3.7. Effect of Dietary CLA Supplementation on HO-1 Expression in Mouse Skin. Significant decreases in HO-1 protein levels in the dietary CLA-supplemented groups were shown at all time points compared with the control group during wound healing (Figure 6).

3.8. Effect of Dietary CLA Supplementation on CuZnSOD Expression in Mouse Skin. Expression levels of CuZnSOD protein in the control group were significantly higher at $24 \mathrm{hr}$ and $48 \mathrm{hr}$ after wounding ( 2 folds) as compared with those in the dietary CLA-supplemented groups (Figure 7). 


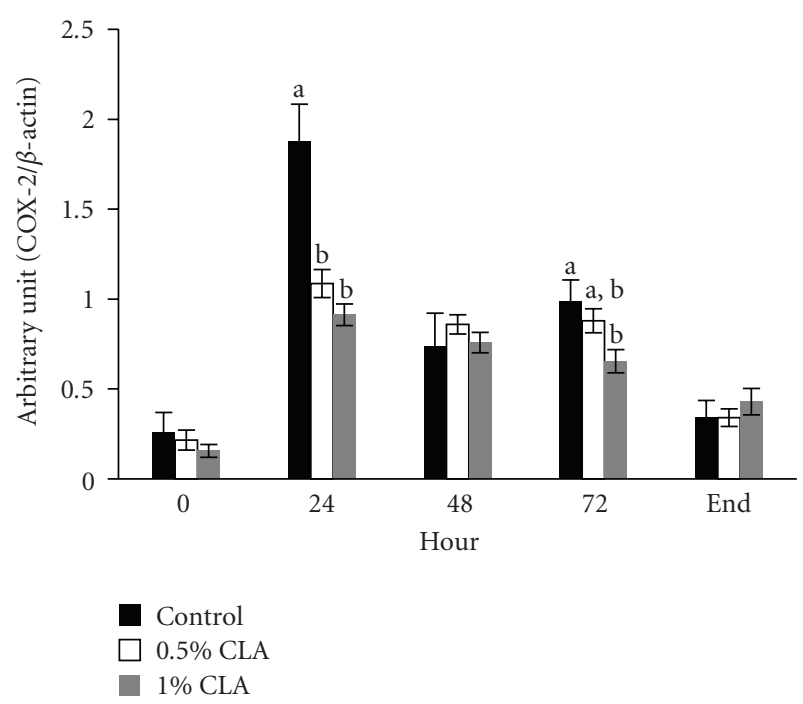

(a)

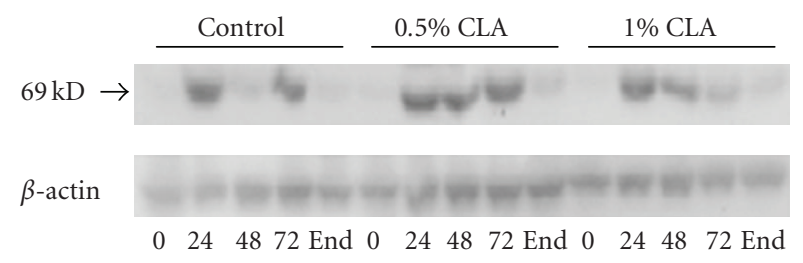

(b)

FIGURE 5: COX-2 protein expression in cutaneous wounds of mice fed diets containing 0 (control), $0.5 \%$, or $1 \%$ CLA for 2 weeks. (a) Quantified COX-2 protein expression levels determined by densitometry. Values are mean \pm SEM; $N=4$ to 6 in each group. Means at a time with a different letter are significantly different, $P<.05$. (b) $0 ; 0 \mathrm{hr}, 24 ; 24 \mathrm{hr}, 48 ; 48 \mathrm{hr}, 72 ; 72 \mathrm{hr}$ after wounding, end (wound is completely closed).

3.9. Effect of Dietary CLA Supplementation on MnSOD Expression in Mouse Skin. Like CuZnSOD, we also detected a significant increase in MnSOD protein in the controls compared to the dietary CLA-supplemented groups at $24 \mathrm{hr}$ and $48 \mathrm{hr}$ after wounding (Figure 8). MnSOD protein levels in the controls were clearly increased after wounding, while no changes were noted in the dietary CLA-supplemented groups.

\section{Discussion}

In these experiments, we investigated the effects of dietary CLA supplementation on molecular events in the early inflammatory stage of cutaneous wound healing using an in vivo model. Our data demonstrated that dietary CLA supplementation decreased weight gain, reduced the levels of both inflammatory and oxidative stress markers at wound sites, and accelerated the wound closure rate.

We found weight loss effects of dietary CLA supplementation in mice as confirmed by previous studies. The effects of CLA in regulating body weight have been supported by several animal studies $[15,18]$. Reduction in body
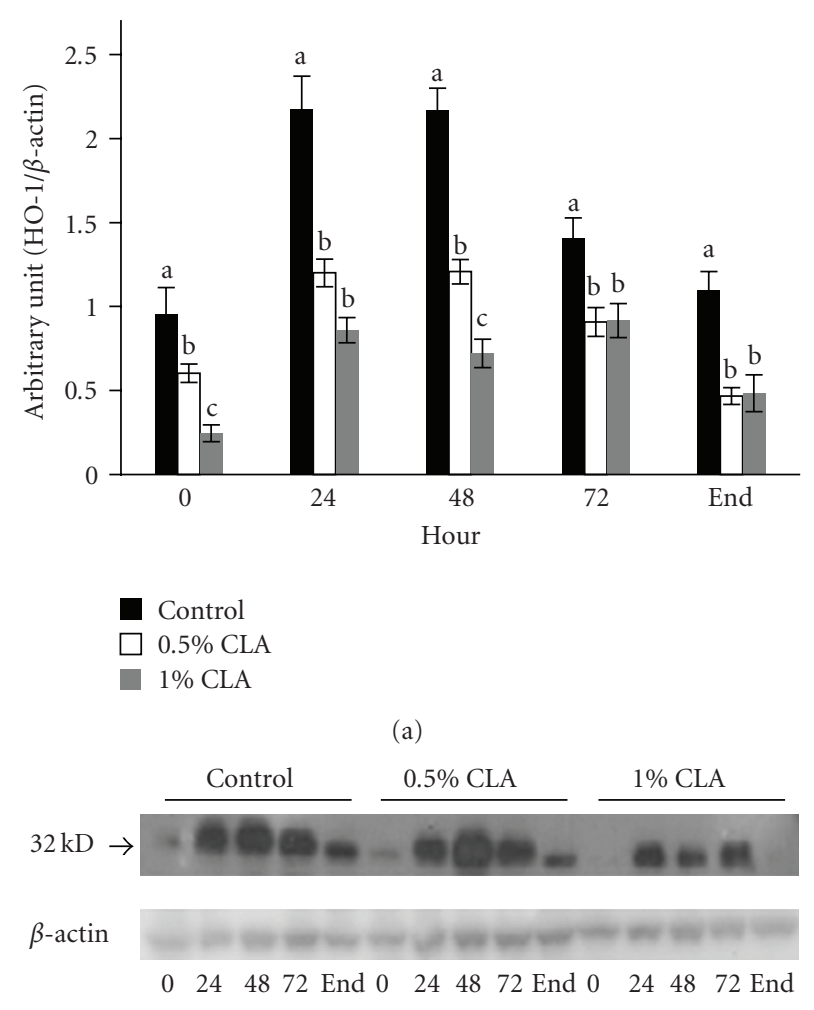

(b)

Figure 6: HO-1 protein expression in cutaneous wounds of mice fed diets containing 0 (control), $0.5 \%$, or $1 \%$ CLA for 2 weeks. (a) Quantified HO-1 protein expression level determined by densitometry. Values are mean \pm SEM; $N=4$ to 6 in each group. Means at a time with a different letter are significantly different, $P<.05$. (b) $0 ; 0 \mathrm{hr}, 24 ; 24 \mathrm{hr}, 48 ; 48 \mathrm{hr}, 72 ; 72 \mathrm{hr}$ after wounding, end (wound is completely closed).

weight seems to be mainly due to the decreased adipose deposition, as a consequence of a gain in lean mass or protein substances. Moreover, the present study supported a correlation between obesity and increased morbidity and mortality after traumatic injury. Previous studies showed that obese trauma patients have a higher likelihood to experience postoperative infectious complications, incidence of multiple organ dysfunction, and longer hospitalization when compared with nonobese patients after acute injury [37-39]. Our date are in accordance with the abovementioned reports since a lower body weight gain by dietary CLA supplementation improved the wound closure rate.

Previous studies showed that dietary CLA enhanced oxidative stability of liver $[40,41]$, which suggested that dietary CLA supplementation increases the ability of protection to oxidative stress and scavenging free radicals and this can explain the decreased MDA levels, the marker of lipid peroxidation, observed in liver of dietary CLA supplemented mice (Figure 2).

To understand part of the molecular mechanisms through which dietary CLA supplementation modifies the rate of the wound closure, we investigated $\mathrm{NF} \kappa \mathrm{B}$ activation 


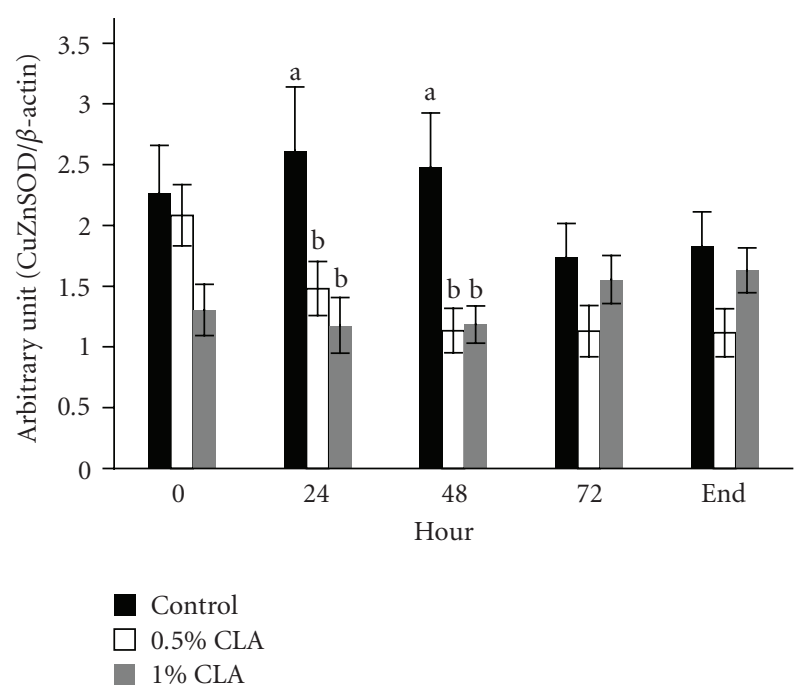

(a)

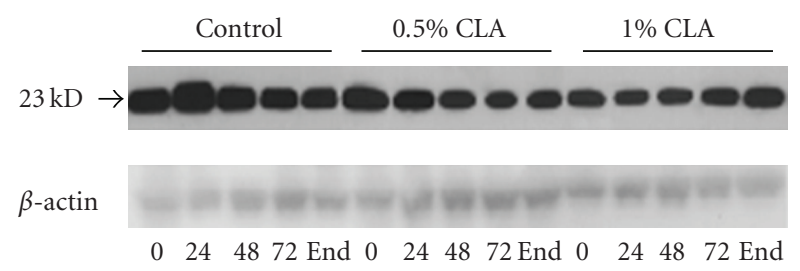

(b)

Figure 7: CuZnSOD protein expression in cutaneous wounds of mice fed diets containing 0 (control), $0.5 \%$, or $1 \%$ CLA for 2 weeks. (a) Quantified CuZnSOD protein expression level determined by densitometry. Values are mean \pm SEM; $N=4$ to 6 in each group. Means at a time with a different letter are significantly different, $P<$ .05 . (b) $0 ; 0 \mathrm{hr}, 24 ; 24 \mathrm{hr}, 48 ; 48 \mathrm{hr}, 72 ; 72 \mathrm{hr}$ after wounding, end (wound is completely closed).

through the expression of $\mathrm{pI} \kappa \mathrm{B} \alpha$. NF $\kappa \mathrm{B}$ is sequestered in the cytoplasm of unstimulated cells bound to the inhibitory protein, $\mathrm{I} \kappa \mathrm{B}[42]$. Exposure of cells to various stimuli such as ROS, proinflammatory cytokines, UV light, or bacterial endotoxins results in $\mathrm{NF} \kappa \mathrm{B}$ activation and then $\mathrm{I} \kappa \mathrm{B}$ is phosphorylated and degraded, promoting the translocation of NF $\kappa B$ to the nucleus where it controls the expression of specific cellular genes associated with host inflammatory and immune response [42]. Our data demonstrated that $\mathrm{pI} \kappa \mathrm{B} \alpha$ protein levels generally were downregulated in mice fed dietary CLA supplementation than in mice fed the control diet (Figure 4). Furthermore, the accelerated rate of wound closure in mice fed the 1\% CLA supplemented diet paralleled the decrease in $\mathrm{pI} \kappa \mathrm{B} \alpha$ protein levels. It is well recognized that the activation of $N F \kappa B$ is redox sensitive and can be inhibited by antioxidants [42]. It was suggested that CLA is an influential antioxidant that shows free radical scavenging activities [28]. Previous studies represented that CLA decreased $\mathrm{NF} \kappa \mathrm{B}$ activation [43], confirming our data suggesting that dietary CLA supplementation may accelerate wound healing as a result of down-regulated $\mathrm{NF} \kappa \mathrm{B}$ activation.

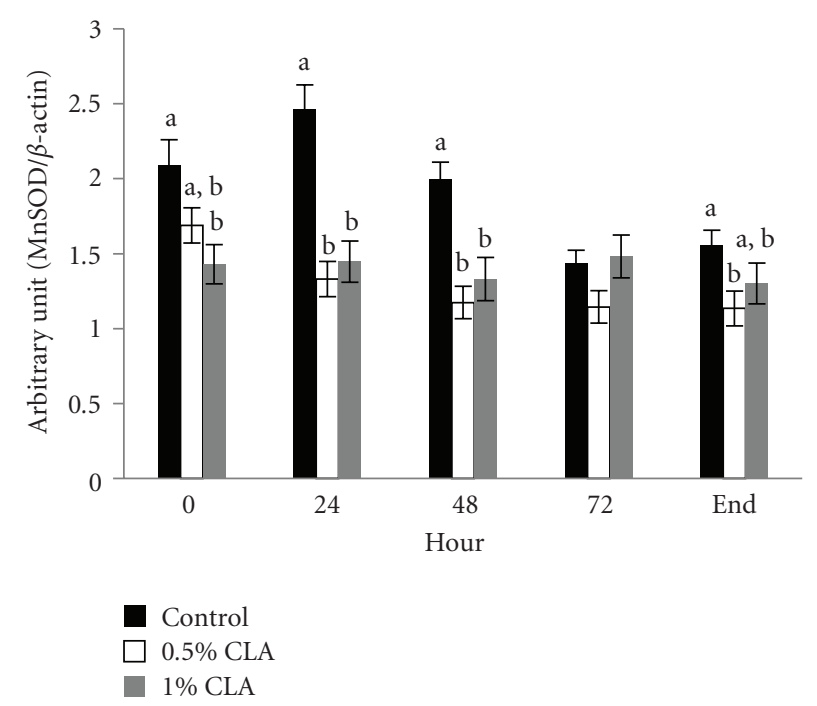

(a)

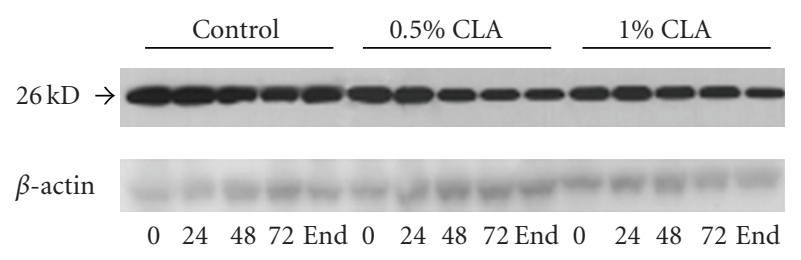

(b)

FIGURE 8: MnSOD protein expression in cutaneous wounds of mice fed diets containing 0 (control), $0.5 \%$, or $1 \%$ CLA for 2 weeks. (a) Quantified MnSOD protein expression level determined by densitometry. Values are mean \pm SEM; $N=4$ to 6 in each group. Means at a time with a different letter are significantly different, $P<.05$. (b) $0 ; 0 \mathrm{hr}, 24 ; 24 \mathrm{hr}, 48 ; 48 \mathrm{hr}, 72 ; 72 \mathrm{hr}$ after wounding, end (wound is completely closed).

To investigate the effect of dietary CLA supplementation on $\mathrm{NF} \kappa \mathrm{B}$ activation and following events during the early inflammatory stage, protein levels of the inflammatory mediator $\mathrm{COX}-2$, a target gene of $\mathrm{NF} \kappa \mathrm{B}$ activation, were examined at different time points. The expression of COX2 is scarcely detectable under normal physiological states. On the contrary, it can be induced by proinflammatory cytokines, bacterial endotoxins, growth factors, and phorbol esters through $\mathrm{NF} \kappa \mathrm{B}$ activation [44]. Because of its biological role in chronic inflammatory diseases [45], it is possible that down-regulated expression levels of COX-2 protein may accelerate the wound healing procedure by reducing inflammatory response. Similar to previous studies [31], we found that dietary CLA supplementation downregulated COX-2 expression. Therefore, this result suggests that dietary CLA supplementation may apply its beneficial effect via modification in the expression levels of inflammatory mediators such as COX-2 during wound healing. Because the activation of $\mathrm{NF} \kappa \mathrm{B}$ is redox sensitive, the antioxidant effect of CLA blocks NF $\kappa \mathrm{B}$ activation and downregulates its downstream target, COX-2.

During the inflammatory phase of wound healing, innate immune cells that are present in the wound produce and 
secrete large amounts of ROS, which are of necessity to protect the organism against invading bacteria [11]. If ROS are produced in excessive amounts or the detoxification of ROS is insufficient, oxidative stress occurs. HO-1 is involved in the cell response against oxidative injury. The present results showed that the levels of HO-1 protein in mice fed dietary CLA supplementations were lower than those in mice fed the control diet. In addition, the levels of CuZnSOD and MnSOD protein in mice fed the dietary CLA supplementation were lower than those in mice fed the control diet. This can suggest that ROS levels be reduced in mice fed dietary CLA compared to the control and this could be the ability of CLA to quench the ROS generated by innate immune cells [28]. The controlled protein expression of several ROSscavenging enzymes such as $\mathrm{HO}-1, \mathrm{CuZnSOD}$, and MnSOD that we observed after skin injury seems to be in contrast to findings of other researchers [46], who found enhanced expression of ROS-detoxifying enzymes at the wound site resulting in improvement of healing by regulating the levels of ROS. Oxidative stress and ROS detoxifying enzymes can always represent a double face. The up-regulation of the enzymes can help wound healing, but from the other side, it can be the consequences of an increased oxidative stress. In our previous work [35], we showed that oxidative stress can slow down the wound healing process and it was parallel to increased HO-1 levels. Therefore, our result of lowered protein expression of ROS-detoxifying enzymes in skin wound healing might be attributed to down-regulated generation of ROS confirmed in decreased MDA level in liver, possibly by dietary CLA supplementation.

\section{Conclusions}

Taken together, the results of this study suggest that dietary CLA supplementation accelerates the early inflammatory response during wound healing. Because of the critical role of $\mathrm{NF} \kappa \mathrm{B}$, which is required for the induction of an inflammatory mediator COX-2 during inflammation, reduced activation of $\mathrm{NF} \kappa \mathrm{B}$ may prevent prolonged inflammatory responses by decreased oxidative stress in CLA supplementation, which is confirmed through HO-1, CuZnSOD, and MnSOD expression.

In conclusion, the current study demonstrated that CLA exerts beneficial effects on the early inflammatory response of cutaneous wound healing through the modulation of inflammatory response and oxidative stress. Therefore, the results may provide critical insight into future nutritional intervention strategies designed to enhance early wound healing not only in people with normal body weight but in overweight or obese people.

\section{Acknowledgment}

This research was supported by a grant from Kyung Hee University (KHU-20061217).

\section{References}

[1] Y. Lim, M. A. Levy, and T. M. Bray, "Dietary supplementation of $\mathrm{N}$-acetylcysteine enhances early inflammatory responses during cutaneous wound healing in protein malnourished mice," Journal of Nutritional Biochemistry, vol. 17, no. 5, pp. 328-336, 2006.

[2] P. Martin, "Wound healing — aiming for perfect skin regeneration," Science, vol. 276, no. 5309, pp. 75-81, 1997.

[3] A. J. Singer and R. A. F. Clark, "Cutaneous wound healing," The New England Journal of Medicine, vol. 341, no. 10, pp. 738746, 1999.

[4] S. Werner and R. Grose, "Regulation of wound healing by growth factors and cytokines," Physiological Reviews, vol. 83, no. 3, pp. 835-870, 2003.

[5] G. Hübner, M. Brauchle, H. Smola, M. Madlener, R. Fässler, and S. Werner, "Differential regulation of proinflammatory cytokines during wound healing in normal and glucocorticoid-treated mice," Cytokine, vol. 8, no. 7, pp. 548556, 1996.

[6] D. M. Simpson and R. Ross, "The neutrophilic leukocyte in wound repair a study with antineutrophil serum," Journal of Clinical Investigation, vol. 51, no. 8, pp. 2009-2023, 1972.

[7] S. J. Leibovich and R. Ross, "The role of the macrophage in wound repair. A study with hydrocortisone and antimacrophage serum," American Journal of Pathology, vol. 78, no. 1, pp. 71-99, 1975.

[8] S. F. Lowry, "Cytokine mediators of immunity and inflammation," Archives of Surgery, vol. 128, no. 11, pp. 1235-1241, 1993.

[9] A. Barbul, "Immune aspects of wound repair," Clinics in Plastic Surgery, vol. 17, no. 3, pp. 433-442, 1990.

[10] B. Meier, H. H. Radeke, S. Selle et al., "Human fibroblasts release reactive oxygen species in response to interleukin-1 or tumour necrosis factor- $\alpha$," Biochemical Journal, vol. 263, no. 2, pp. 539-545, 1989.

[11] M. Schäfer and S. Werner, "Oxidative stress in normal and impaired wound repair," Pharmacological Research, vol. 58, no. 2, pp. 165-171, 2008.

[12] F. A. D. T. G. Wagener, H. E. van Beurden, J. W. von den Hoff, G. J. Adema, and C. G. Figdor, "The heme-heme oxygenase system: a molecular switch in wound healing," Blood, vol. 102, no. 2, pp. 521-528, 2003.

[13] M. Arnold and A. Barbul, "Nutrition and wound healing," Plastic and Reconstructive Surgery, vol. 117, no. 7, pp. 42S-58S, 2006.

[14] Y. Lim, M. Levy, and T. M. Bray, "Dietary zinc alters early inflammatory responses during cutaneous wound healing in weanling CD-1 mice," Journal of Nutrition, vol. 134, no. 4, pp. 811-816, 2004.

[15] M. W. Pariza, Y. Park, and M. E. Cook, "The biologically active isomers of conjugated linoleic acid," Progress in Lipid Research, vol. 40, no. 4, pp. 283-298, 2001.

[16] J. M. Griinari, B. A. Corl, S. H. Lacy, P. Y. Chouinard, K. V. V. Nurmela, and D. E. Bauman, "Conjugated linoleic acid is synthesized endogenously in lactating dairy cows by $\Delta 9$ desaturase," Journal of Nutrition, vol. 130, no. 9, pp. 22852291, 2000.

[17] M. W. Pariza, S. H. Ashoor, F. S. Chu, and D. B. Lund, "Effects of temperature and time on mutagen formation in pan fried hamburger," Cancer Letters, vol. 7, no. 2-3, pp. 63-69, 1979.

[18] Y. Park, K. J. Albright, W. Liu, J. M. Storkson, M. E. Cook, and M. W. Pariza, "Effect of conjugated linoleic acid on body composition in mice," Lipids, vol. 32, no. 8, pp. 853-858, 1997. 
[19] R. J. Nicolosi, E. J. Rogers, D. Kritchevsky, J. A. Scimeca, and P. J. Huth, "Dietary conjugated linoleic acid reduces plasma lipoproteins and early aortic atharosclerosis in hypercholasterolemic hamsters," Artery, vol. 22, no. 5, pp. 266-277, 1997.

[20] K. N. Lee, D. Kritchevsky, and M. W. Parizaa, "Conjugated linoleic acid and atherosclerosis in rabbits," Atherosclerosis, vol. 108, no. 1, pp. 19-25, 1994.

[21] J. W. Ryder, C. P. Portocarrero, X. M. Song et al., "Isomerspecific antidiabetic properties of conjugated linoleic acid: improved glucose tolerance, skeletal muscle insulin action, and UCP-2 gene expression," Diabetes, vol. 50, no. 5, pp. 1149$1157,2001$.

[22] K. L. Houseknecht, J. P. V. Heuvel, S. Y. Moya-Camarena et al., "Dietary conjugated linoleic acid normalizes impaired glucose tolerance in the Zucker diabetic fatty fa/fa rat," Biochemical and Biophysical Research Communications, vol. 244, no. 3, pp. 678-682, 1998.

[23] M. Yang and M. E. Cook, "Dietary conjugated linoleic acid decreased cachexia, macrophage tumor necrosis factor$\alpha$ production, and modifies splenocyte cytokines production," Experimental Biology and Medicine, vol. 228, no. 1, pp. 51-58, 2003.

[24] Y. Yu, P. H. Correll, and J. P. V. Heuvel, "Conjugated linoleic acid decreases production of pro-inflammatory products in macrophages: evidence for a PPAR $\gamma$-dependent mechanism," Biochimica et Biophysica Acta, vol. 1581, no. 3, pp. 89-99, 2002.

[25] Y. Iwakiri, D. A. Sampson, and K. G. D. Allen, "Suppression of cyclooxygenase-2 and inducible nitric oxide synthase expression by conjugated linoleic acid in murine macrophages," Prostaglandins Leukotrienes and Essential Fatty Acids, vol. 67, no. 6, pp. 435-443, 2002.

[26] C. C. Miller, Y. Park, M. W. Pariza, and M. E. Cook, "Feeding conjugated linoleic acid to animals partially overcomes catabolic responses due to endotoxin injection," Biochemical and Biophysical Research Communications, vol. 198, no. 3, pp. 1107-1112, 1994.

[27] L. Yu, D. Adams, and M. Gabel, "Conjugated linoleic acid isomers differ in their free radical scavenging properties," Journal of Agricultural and Food Chemistry, vol. 50, no. 14, pp. 4135-4140, 2002.

[28] L. Yu, "Free radical scavenging properties of conjugated linoleic acids," Journal of Agricultural and Food Chemistry, vol. 49, no. 7, pp. 3452-3456, 2001.

[29] Y. H. Leung and R. H. Liu, "trans-10,cis-12-conjugated linoleic acid isomer exhibits stronger oxyradical scavenging capacity than cis-9,trans-11-conjugated linoleic acid isomer," Journal of Agricultural and Food Chemistry, vol. 48, no. 11, pp. 54695475, 2000.

[30] C. Noli, G. Carta, L. Cordeddu, M. P. Melis, E. Murru, and S. Banni, "Conjugated linoleic acid and black currant seed oil in the treatment of canine atopic dermatitis: a preliminary report," Veterinary Journal, vol. 173, no. 2, pp. 413-421, 2007.

[31] D.-M. Hwang, J. K. Kundu, J.-W. Shin, J.-C. Lee, H. J. Lee, and Y.-J. Surh, "cis-9,trans-11-conjugated linoleic acid down-regulates phorbol ester-induced NF- $\kappa \mathrm{B}$ activation and subsequent COX-2 expression in hairless mouse skin by targeting I $\kappa \mathrm{B}$ kinase and PI3K-Akt," Carcinogenesis, vol. 28, no. 2, pp. 363-371, 2007.

[32] A. M. Mercado, N. Quan, D. A. Padgett, J. F. Sheridan, and P. T. Marucha, "Restraint stress alters the expression of interleukin1 and keratinocyte growth factor at the wound site: an in situ hybridization study," Journal of Neuroimmunology, vol. 129, no. 1-2, pp. 74-83, 2002.
[33] H. Ohkawa, N. Ohishi, and K. Yagi, "Assay for lipid peroxides in animal tissues by thiobarbituric acid reaction," Analytical Biochemistry, vol. 95, no. 2, pp. 351-358, 1979.

[34] I. Salminen, M. Mutanen, M. Jauhiainen, and A. Aro, "Dietary trans fatty acids increase conjugated linoleic acid levels in human serum," Journal of Nutritional Biochemistry, vol. 9, no. 2, pp. 93-98, 1998.

[35] Y. Lim, A. D. Phung, A. M. Corbacho et al., "Modulation of cutaneous wound healing by ozone: differences between young and aged mice," Toxicology Letters, vol. 160, no. 2, pp. 127-134, 2006.

[36] G. Valacchi, A. van der Vliet, B. C. Schock et al., "Ozone exposure activates oxidative stress responses in murine skin," Toxicology, vol. 179, no. 1-2, pp. 163-170, 2002.

[37] D. J. Ciesla, E. E. Moore, J. L. Johnson, J. M. Burch, C. C. Cothren, and A. Sauaia, "Obesity increases risk of organ failure after severe trauma," Journal of the American College of Surgeons, vol. 203, no. 4, pp. 539-545, 2006.

[38] C. V. R. Brown, A. L. Neville, P. Rhee, A. Salim, G. C. Velmahos, and D. Demetriades, "The impact of obesity on the outcomes of 1,153 critically injured blunt trauma patients," The Journal of Trauma, vol. 59, no. 5, pp. 1048-1051, 2005.

[39] J. C. Duchesne, R. E. Schmieg Jr., J. D. Simmons, T. Islam, C. L. McGinness, and N. E. McSwain Jr., "Impact of obesity in damage control laparotomy patients," The Journal of Trauma, vol. 67, no. 1, pp. 108-114, 2009.

[40] S. A. Livisay, S. Zhou, C. Ip, and E. A. Decker, "Impact of dietary conjugated linoleic acid on the oxidative stability of rat liver microsomes and skeletal muscle homogenates," Journal of Agricultural and Food Chemistry, vol. 48, no. 9, pp. 4162-4167, 2000.

[41] H. J. Zhang, Y. D. Tian, Y. M. Guo, and J. M. Yuan, "Dietary conjugated linoleic acid improves antioxidant capacity in broiler chicks," British Poultry Science, vol. 49, no. 2, pp. 213221.

[42] P. J. Barnes and I. M. Adcock, "NF- $\kappa$ B: a pivotal role in asthma and a new target for therapy," Trends in Pharmacological Sciences, vol. 18, no. 2, pp. 46-50, 1997.

[43] W.-L. Cheng, C.-K. Lii, H.-W. Chen, T.-H. Lin, and K.-L. Liu, "Contribution of conjugated linoleic acid to the suppression of inflammatory responses through the regulation of the NF$\kappa \mathrm{B}$ pathway," Journal of Agricultural and Food Chemistry, vol. 52, no. 1, pp. 71-78, 2004.

[44] W. L. Smith, D. L. DeWitt, and R. M. Garavito, "Cyclooxygenases: structural, cellular, and molecular biology," Annual Review of Biochemistry, vol. 69, pp. 145-182, 2000.

[45] Y.-J. Surh, K.-S. Chun, H.-H. Cha et al., "Molecular mechanisms underlying chemopreventive activities of antiinflammatory phytochemicals: down-regulation of COX-2 and iNOS through suppression of NF- $\kappa \mathrm{B}$ activation," Mutation Research, vol. 480-481, pp. 243-268, 2001.

[46] U. auf dem Keller, A. Kümin, S. Braun, and S. Werner, "Reactive oxygen species and their detoxification in healing skin wounds," Journal of Investigative Dermatology Symposium Proceedings, vol. 11, no. 1, pp. 106-111, 2006. 


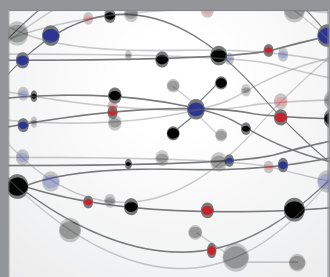

The Scientific World Journal
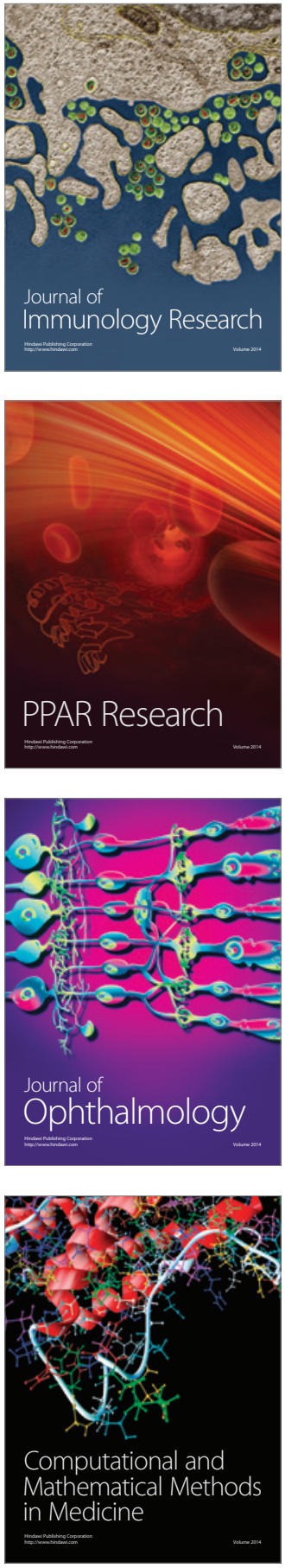

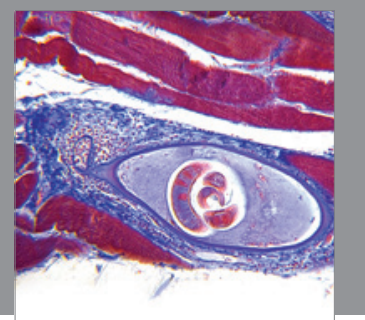

Gastroenterology

Research and Practice
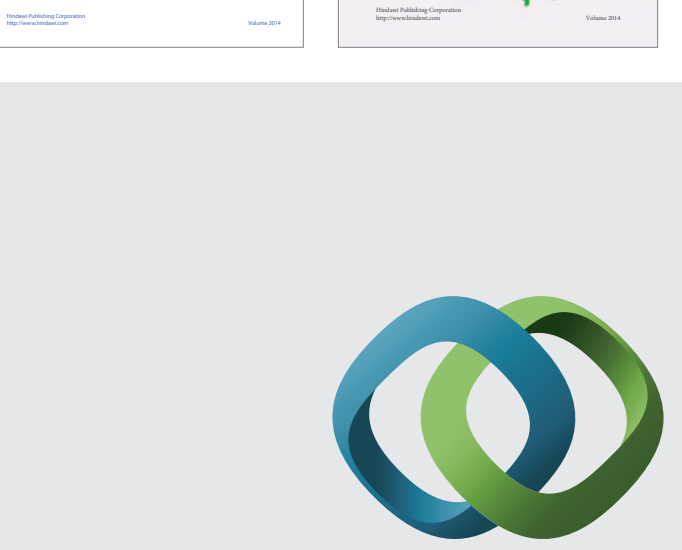

\section{Hindawi}

Submit your manuscripts at

http://www.hindawi.com
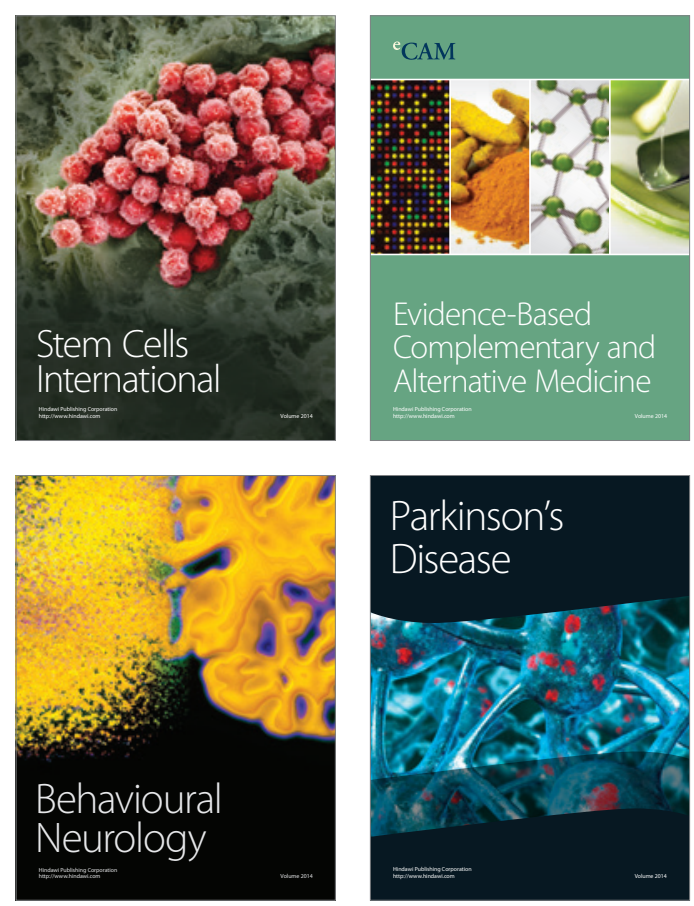

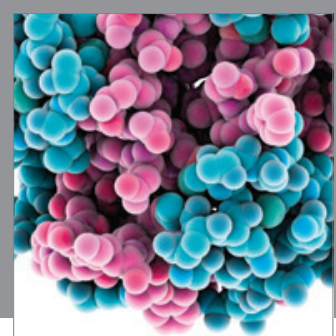

Journal of
Diabetes Research

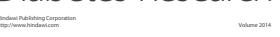

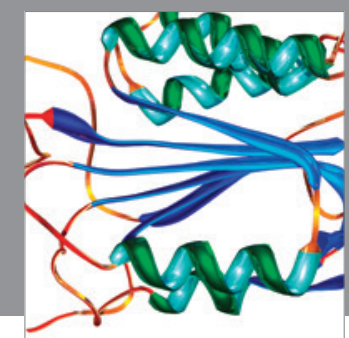

Disease Markers
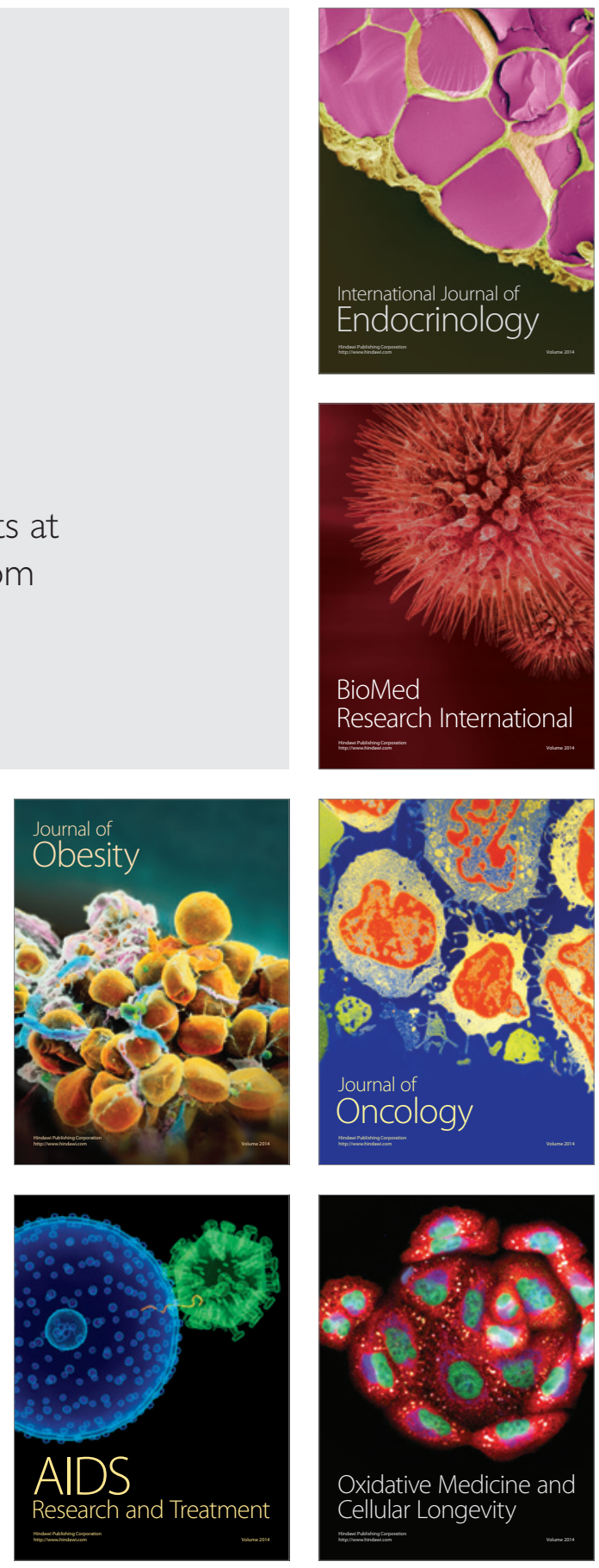